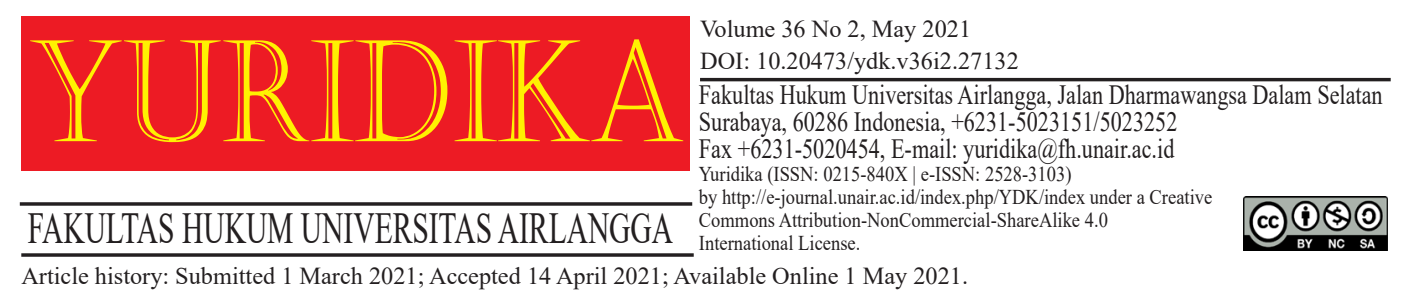

\title{
The Intersection of COVID-19 and Mental Health: What's the Matter with Ethics?
}

\author{
Siti Hafsyah Idris, Nor Jannah Nasution Raduan, Nurul Azreen Hashim , \\ Nadiah Thanthawi Jauhari and Roslinda Mohd Subbian \\ sitihafsyah@salam.uitm.edu.my \\ Universiti Teknologi MARA
}

\begin{abstract}
As the coronavirus (COVID-19) pandemic rapidly sweeps the world, it induces a considerable degree of fear, worry and concern in the population at large, despite the measures taken to contain the spread of the disease through quarantine. Health care providers, the elderly and individuals with underlying health conditions are the most vulnerable to the disease. Nations, even those with advanced resources of medical science, have underestimated the perils of the pandemic. Efforts are focused on understanding the epidemiology, clinical features, transmission patterns and management of the coronavirus disease. One aspect often overlooked, however, is the mental health crisis underpinning the effects of self-isolation/quarantine and the deaths of loved ones, a crisis which becomes increasingly urgent as the number of positive cases in Malaysia grows exponentially each day. With strict preventive measures and restrictions enacted by the Malaysian Government in the form of the nationwide Movement Control Order, the citizens are experiencing a range of psychological and emotional reactions, including the fear and uncertainty of being one of the infected. Many studies have been conducted to identify the state of mental health of vulnerable individuals during this calamity. This raises both ethical concerns and legal issues with regard to the rights of individuals enduring mental illness. This paper explores the ethical issues involved in the research on mental health during the COVID-19 pandemic and the regulatory mechanisms which protect the rights of the persons who have symptoms of mental illness.
\end{abstract}

Keywords: Medical Ethics; COVID-19; Ethical Issues; Regulatory Mechanisms; Rights; Psychology.

\section{Introduction}

The nature of COVID-19 has prompted policymakers worldwide to take unprecedented action. The outrageous severity of the disease has led to billions of citizens being compelled to stay at home with no end in sight even after social distancing restrictions have eased. Many residents found it extraordinarily difficult 
to follow the government-sanctioned Movement Control Order $(\mathrm{MCO})^{1}$. The various losses accompanying the spread of COVID-19 have exacerbated mental health issues. Many are crying for their lost way of life, others are mourning their loss of employment, and many more are grieving over their separation from family members and their loss of loved ones. Some of those who have been affected the worst are marginalized individuals, such as those dealing with psychiatric disorders, the disabled, those with serious medical problems and those from low-income communities. ${ }^{2}$ Increased social isolation, loneliness, health anxiety, stress and an economic decline are a perfect storm for damaging individuals' mental wellbeing. ${ }^{3}$

On top of that, official government departments, such as Malaysia's Ministry of Health, strive to improve the public's awareness of prevention and intervention strategies by providing daily updates on case surveillance and the number of active cases on websites and social media. ${ }^{4}$ Many self-media accounts and netizens also release and transfer related information on social media, such as Facebook, Instagram and Twitter. However, social media information may lead to 'fake news' overload, which may increase mental health problems. ${ }^{5}$

An increasing number of citizens have needed aid. 'Safer at home' is an excellent guideline for those infected with COVID-19, but 'home' may not be a secure environment for others. As domestic violence levels tend to increase when victims feel lonely and depressed, staying at home is an unhealthy environment for them. Experts have cautioned that such effects will persist far into the future, long after the latest lockdown phase is eased. The scale of this problem is too severe to

\footnotetext{
${ }^{1}$ Emily A Holmes and others, 'Multidisciplinary Research Priorities for the COVID-19 Pandemic: A Call for Action for Mental Health Science' (2020) 7 Lancet Psychiatry.[547-560].

${ }^{2}$ Malaysiakini, 'Battling the Beast within: The Psychological Trauma of Covid-19' (Malaysiakini, 2020) <https://www.malaysiakini.com/news/522732> accessed 11 September 2020.

${ }^{3}$ News Strait Times, 'Covid-19 to Have "profound" Mental Health Fallout' (News Strait Times, 2020) <https://www.nst.com.my/world/world/2020/04/584739/covid-19-have-profoundmental-health-fallout $>$ accessed 10 June 2020.

${ }^{4}$ Yaping Bao and others, '2019-NCoV Epidemic: Address Mental Health Care to Empower Society' (2019) 395 Lancet.[e37-e38].

${ }^{5}$ Kalina Bontcheva and others, 'Social Media and Information Overload: Survey Results' (arXiv, 2013) <https://arxiv.org/pdf/1306.0813.pdf> accessed 10 June 2020.; Florian Roth and Gabriel Brönnimann, Focal Report 8: Risk Analysis Using the Internet for Public Risk Communication (Center for Security Studies 2013).
} 
ignore as it may have a broader impact on society. A lack of action in this regard has threatened an outbreak of mental health problems such as anxiety and depression in addition to increased reports of domestic violence. ${ }^{6}$ With the new form of daily life, unprecedented moral, ethical and legal concerns are surfacing.

The World Health Organization (WHO) released in February 2020 lists of research priorities and actions to combat the epidemic of COVID-19, which were agreed upon during a global research and innovation forum aiming to curb the outbreak. The COVID-19 forum in Geneva has identified nine thematic which include ethical considerations for research and the integration of the social sciences into the outbreak response. ${ }^{7}$

\section{Ethical Concerns}

In the new normal, due to high levels of uncertainty, anxiety, social distancing pressures and financial troubles, the risk of mental health is likely to increase worldwide. Most policymakers now include mental health research in reaction to the COVID-19 pandemic. ${ }^{8}$ However, ethical issues need to be considered when researching mental health as one of the broader effects of the global pandemic.

The ethical deliberation of this paper is principally based on the principlism approach as first described by Beauchamp and Childress in 1979, which will be applied in this paper to the actual situation of mental health surveys during COVID-19. The principlism approach is divided into four categories of basic principles. ${ }^{9}$ All principles need to remain consistent with human rights as stated in the Universal Declaration of Human Rights and the Convention on Persons with Disabilities. ${ }^{10}$

6 The Star, 'Implement Emergency Response to Domestic Violence amid Covid-19 Crisis' (The Star, 2020) <https://www.thestar.com.my/opinion/letters/2020/04/13/implement-emergencyresponse-to-domestic-violence-amid-covid-19-crisis $>$ accessed 10 June 2020.

${ }^{7}$ World Health Organizations, 'World Experts and Funders Set Priorities for COVID-19 Research' (World Health Organization, 2020) < https://www.who.int/news-room/detail/12-02-2020world-experts-and-funders-set-priorities-for-covid-19-research> accessed 10 June 2020.

${ }^{8}$ Emily A Holmes and others (n 1).

9 Tom L. Beauchamp and James F. Childress, Principles of Biomedical Ethics (6th edn, Oxford University Press 2009).

${ }^{10}$ UN General Assembly, 'Convention on the Rights of Persons with Disabilities' (UN General Assembly, 2006) <https://www.refworld.org/docid/4680cd212.html> accessed 10 June 2020. 


\section{Respect for Autonomy}

Respect for autonomy is 'a standard for accepting and promoting autonomous decisions, defining the need to value autonomous individuals' right to make decisions'. ${ }^{11}$ Mental health research is a vital part of the response to the pandemic. Still, some studies do not provide sufficient information to allow fully informed consent or to measure mood before or after participation. There is also a lack of studies to provide any procedural guidance other than potentially anxiety-provoking messages about COVID-19. An example of such guidance may have included that it is important not to attempt any mood mitigation or debriefing to help stabilize anyone who has become distressed after participation. The presence of multiple mental health assessments in the population poses legal questions about whether they are compatible with the ethical principles set forth under mental health ethics codes to preserve the privacy of mental disorder patients. While the studies have potential, mental health researchers face various ethical challenges. They are often liable for ensuring that participants are competent and ready to consent to participation in the study. For most cases, however, the question of sound judgements is not that simple. Individuals with cognitive disabilities might have difficulty interpreting a research study and providing informed consent, but they may want to participate. Many studies gather personal details regarding medical history and personal data that, if published, may result in mental, financial or legal damage. Therefore, between an obligation to defend disadvantaged people and the responsibility to practice the duty of care to protect their privacy lies the friction between ethics and research.

According to the Principles of Good Research Practice in COVID-19 research, ${ }^{12}$ research on human participants should maintain high standards of ethical practice, including seeking the approval of a research ethics committee. ${ }^{13}$ These participants

\footnotetext{
${ }^{11}$ Tom L. Beauchamp and James F. Childress (n 9).

${ }^{12}$ Emily A Holmes and others (n 1).

${ }^{13}$ Lawrence O Gostin and others, 'Ethical and Legal Challenges Posed by Severe Acute Respiratory Syndrome: Implications for the Control of Severe Infectious Disease Threats' (2003) 290 JAMA $<$ https://doi.org/10.1001/jama.290.24.3229>. 3229, 3237; Ellen Townsend and others, 'Key Ethical Questions for Research during the COVID-19 Pandemic' (2020) 7 Lancet Psychiatry $<$ https://www. thelancet.com/journals/lanpsy/article/PIIS2215-0366(20)30150-4/fulltext>.[381- 383].
} 
are persons whose natural or de facto capacity to consent is undermined due to their mental disorder, whether or not they have a legally recognized limitation or an augmented ability to act. Hence, the consent of a person with a mental disorder is in question, and it is therefore necessary to consider the person's capacity to make an autonomous decision regarding possible help and interventions.

\section{Non-Maleficence and Beneficence}

To cause harm is always wrong prima facie. ${ }^{14}$ Aside from the obligation to not cause harm, it is imperative not to subject others to the unnecessary risk of suffering it. ${ }^{15}$ The governing authorities should adequately assess the collection of research data on mental health subjects' circumstances and the predictable consequences of inflicting unnecessary harm. Since the beneficence principle is motivated by the imperative need to obtain the greater good for the patient, discretion in this context is replaced by the obligation to aid the patient. The patient's capacity for consent may have been weakened. Hence, while the free and informed consent of the potential subject is always required, it is not always possible, as is the case with some patients with mental illness. The moral imperative of encouraging positive behaviour requires acting for the patient's greatest benefit in all situations to prevent anyone from taking advantage of his or her disability and to reduce avoidable suffering. However, there are person/subjects who are incapable of deciding whose rights must be safeguarded. Hence, ensuring human care and effective mental health intervention for everyone, and especially for those most in need, seems, as a last resort, a responsibility for the government to handle with care.

\section{Justice}

Society has the right and duty to exercise appropriate and constructive democratic pressures to influence the legislator, and the government in turn has the

${ }^{14}$ A. Skelton, The Stanford Encyclopedia of Philosophy (Summer 201, Metaphysics Research Lab, Stanford University 2012).

${ }^{15} \mathrm{ibid}$. 
duty to implement applicable and coherent policies. The care of the incapable person is an end, not a means. As a duty of social justice, the patient's esteemed integrity as a matter of rights also demands effective guardianship. The psychological dimension is a continuum independent of the individual's integrity. That is, the patient does not lose an iota of integrity from any illness or condition, even if this condition seriously affects his or her affectivity or judgement. Consequently, a duty of dignity exists on behalf of the incompetent patient, for whom the necessary social intervention to preserve his or her reputation must be provided.

Benefits must be high and risk minimized for a study to be considered ethical. The research group needs to be explicit about who will benefit from the research and how to improve policy and practice within a certain timeframe. Clearly, with the rise of online research, ethics committees worldwide have a vital role in assessing these issues. With social distancing and lockdowns, positive digital responses are critical. Globally, mental health services need to collaborate electronically and remotely to meet patient needs. The research community still needs to respond to the COVID-19 pandemic effectively, but what it does must be ethical.

\section{COVID-19 Mental Health Impact in Malaysia}

The impact on mental health due to the COVID-19 pandemic may be a result of social distancing practice and the disruption of a social rhythm that commonly used to act as a coping mechanism for stress. Apart from that, fear and anxiety centring on COVID-19 itself and psychological sequelae from the loss of jobs and financial difficulties increase the risk of anxiety and depression. There has also been a mental health impact on existing poor and vulnerable populations, including a higher risk of relapse among individuals with serious mental illness, increased domestic abuse, and worsening existing illnesses like post-traumatic stress disorder and obsessive-compulsive disorder. ${ }^{16}$

\footnotetext{
${ }^{16}$ Hemavathi Shanmugam and others, 'Impacts of COVID-19 Pandemic on Mental Health in Malaysia: A Single Thread of Hope’ (2020) 29 Malaysian Journal of Psychiatry.
} 
A study done in April 2020 found that 45 per cent of 1,084 Malaysian respondents were experiencing varying levels of anxiety and depression during the MCO period. The psychological hotline Befrienders reported that 34 per cent of the 4,142 calls that they received between March 18 and May 16 were related to the COVID-19 pandemic, and over a third of the calls were suicidal. The Health Ministry also reported that it received some 2,500 phone calls and more than 1,000 WhatsApp messages between March 28 and April 12, during the early days of the MCO, on its Psychological First Aid hotline. ${ }^{17}$

Studies conducted among undergraduate university students in Malaysia found that some students had developed some degree of anxiety, but others were emotionally stable due to positive coping mechanisms. ${ }^{18}$ Significant associated factors with higher anxiety levels among university students were female gender, younger age, management studies and isolation. ${ }^{19}$

The health care workers or medical frontliners face a higher risk of mental health impact due to COVID-19. Those who are already facing daily stresses may begin developing physical and psychological fatigue, burnout and severe mental health issues. ${ }^{20}$ Psychological support in the form of psychological first aid and online counselling services was provided for the frontliners. Remote psychological first aid via mobile application and phone calls was also introduced to limit face-toface consultation to reduce the risk of COVID-19 transmission and to allow them to return to psychological health without being stigmatized. ${ }^{21}$

${ }^{17}$ The Straits Times, 'Covid-19 Crisis Taking a Toll on Malaysians' Mental Health' (The Straits Times, 2020) <https:/www.straitstimes.com/asia/se-asia/covid-19-crisis-taking-a-toll-onmalaysians-mental-health $>$ accessed 11 September 2020.

${ }^{18} \mathrm{~V}$. Kobbin and others, 'Fear, Anxiety and Coping Mechanism During COVID-19 Pandemic Among Undergraduate' (2020) 5 International Journal of Biomedical and Clinical Sciences.[217$228]$.

${ }^{19}$ S. Sundarasen and others, 'Psychological Impact of COVID-19 and Lockdown among University Students in Malaysia: Implications and Policy Recommendations’ (2020) 17 International Journal of Environmental Research and Public Health < http://dx.doi.org/10.3390/ijerph17176206>. [6206].

${ }^{20}$ Malaysiakini (n 2).

${ }^{21}$ A.H. Sulaiman and others, 'Development of a Remote Psychological First Aid Protocol for Healthcare Workers Following the COVID-19 Pandemic in a University Teaching Hospital' (2020) 8 Malaysia Healthcare <http://dx.doi.org/10.3390/healthcare8030228>.[228]. 
Severe mental illness (SMI) is the term used to describe a group of mental disorders, namely, schizophrenia, bipolar disorder and major depressive disorder. However, it may also include any mental illness causing functional impairment. In 2020, as COVID-19 hit the world, everyone passed through a state of grief, with many striving through its psychological impact. However, not many reports have highlighted findings about those with existing severe mental illness. People with SMI are a vulnerable population. They are expected to be at higher risk of a more severe psychological impact from COVID-19 due to pre-existing mental health issues. Physical distancing and movement-restricted control may affect patients with SMI to an even greater extent due to change of environment, disruption of services, increased stress and isolation. ${ }^{22}$

COVID-19 infection may lead to worse outcomes for the SMI population than the general population. Severe results include acute respiratory distress syndrome. ${ }^{23}$ This is due to the risk factors for severe infection being highly prevalent in the SMI population, such as cardiovascular disease, obesity and chronic obstructive pulmonary disease. ${ }^{24}$ In Malaysia, there is scarce evidence of the impact of COVID-19 among the SMI population. Reports from studies worldwide summarized the following three significant effects of COVID-19 on SMI: 1) admission to the isolation ward for suspected COVID-19 patients will be a potential stressor for schizophrenia patients, ${ }^{25}$ 2) people with SMI in the community who do not have COVID-19 may have the risk of suffering higher psychological distress such as non-specific stress,

\footnotetext{
${ }^{22}$ Sarah Barber and others, 'Severe Mental Illness and Risks from COVID-19' (The Centre for Evidence-Based Medicine, 2020) <https:/www.cebm.net/covid-19/severe-mental-illness-andrisks-from-covid-19/> accessed 18 September 2020.

${ }^{23}$ World Health Organization, 'Mental Health and Psychosocial Considerations during the COVID-19 Outbreak' (World Health Organization, 2020) <https://www.who.int/docs/default-source/coronaviruse/mental-health-considerations.pdf $>$ accessed 10 September 2020.

${ }^{24}$ Mark Ashworth and others, 'Physical Health in Severe Mental Illness' (2017) 67 British Journal of General Practice <https://doi.org/10.3399/bjgp17X692621>.[436-437].

${ }^{25}$ Xuebing Liu and others, 'Clinical Characteristics of Hospitalized Patients with Schizophrenia Who Were Suspected to Have Coronavirus Disease (COVID-19) in Hubei Province, China' (2020) 33 General psychiatry <https://doi.org/10.1136/gpsych-2020-100222>.
} 
anxiety, depression or sleep disturbances compared to the general population ${ }^{26}$, and 3) there is data suggestive of a range of COVID-19-related psychopathology in routinely collected clinical notes in one setting. ${ }^{27}$ With this knowledge at hand, it is vital to assist and support the SMI population in Malaysia during the COVID-19 pandemic and to obtain more research and evidence on the psychological impact of COVID-19 in the SMI population in Malaysia.

\section{Regulatory Mechanisms in Addressing Mental Health Issues in Malaysia}

\section{a) Mental Health Act 2001 and the Mental Health Regulations 2010}

The introduction of the Mental Health Act 2001 and the Mental Health Regulations 2010 in Malaysia further streamlined the provision of psychiatric care by the private and government sectors. This Act has provision for mental health delivery in three facilities, namely Psychiatry Hospitals, Psychiatry Nursing Homes and Community Mental Health Centres. It has addressed delivering comprehensive care, treatment, control, protection and rehabilitation of those with mental disorders. Nonetheless, the Act does not explicitly address the ethical issues regarding the privacy and data information in mental health research during COVID-19. Hence, the Manual on Mental Health and Psychosocial Response to Disaster in Community Mental Health Unit Non-Communicable Disease Section Disease Control Division Ministry of Health Malaysia 2013 could be referred to regarding the matter.

This training manual on mental health and psychosocial response to disasters in the community was developed based on references and resources provided by mental health experts from psychiatric services including Mental Health Unit, NCD Section, Disease Control Division, Ministry of Health and the WHO in 2013.

\footnotetext{
${ }^{26}$ Felice Lasevoli and others, 'Psychological Distress in Patients with Serious Mental Illness during the COVID-19 Outbreak and One-Month Mass Quarantine in Italy' (Psychological Medicine, 2020) < https://doi.org/10.1017/S0033291720001841>. 1, 3; F. Hao, Do Psychiatric Patients Experience More Psychiatric Symptoms during COVID-19 Pandemic and Lockdown? A Case-Control Study with Service and Research Implications for Immunopsychiatry (Brain, behavior, and immunity 2020).

${ }^{27}$ C. Rohde and others, Psychiatric Symptoms Related to the COVID-19 Pandemic (medRxiv 2020).
} 
However, it is not so easy to identify psychological problems among victims. Most of the affected people may not show any response yet need psychological aid. The objective of this manual is to recruit and train a Mental Health and Psychosocial Response Team (MHPRT) with basic disaster response skills to prepare them for assisting the community during a disaster; to provide basic knowledge of mental health and psychosocial responses to disaster; to equip MHPRT with disaster management skills in helping the community in preparing for and coping with disaster as well to establish contact and networking for referral purposes. ${ }^{28}$

Nevertheless, it is still unclear whether COVID-19 is within the purview of this disaster description manual. Whether to interpret this manual as a guideline for improving sufficiently trained behavioural health professionals in vulnerable communities to reduce long-term psychological distress risk is vague. Regardless, the Government has taken steps to support those fighting this psychosocial war.

\section{b) Mental Health and Psychosocial Support Interventions in Malaysia During COVID-19 Pandemic - Guidelines COVID-19 Management No. 5/2020}

Ministry of Health Malaysia had included the standard operating procedure of Mental Health and Psychosocial Support (MHPSS) as Annexe 33 in Guidelines of COVID-19 Management. MHPSS refers to any local or outside support that aims to protect or promote psychosocial wellbeing or prevent or treat mental disorders. Support may include interventions in health and education or interventions that are community-based. The 'MHPSS Problems' is a term that encompasses social problems, emotional distress, common mental disorders (such as depression and post-traumatic stress disorder), severe mental disorders (such as psychosis), alcohol and substance abuse and intellectual disability. ${ }^{29}$

${ }^{28}$ Zuhaira Nadia Zulkipli and others, 'Covid-19 Anxiety: Malaysian Regulatory Mechanisms On Mental Health' (2020) 29 International Journal of Advanced Science and Technology <http:// sersc.org/journals/index.php/IJAST/article/view/12723>.[2472-2477].

${ }^{29}$ Ministry of Health Malaysia, 'Annexe 33 Mental Health and Psychosocial Support in COVID-19' (Ministry of Health Malaysia, 2020) < https://www.moh.gov.my/moh/resources/Penerbitan/Garis Panduan/COVID19/Annex_33_Mental_health_and_Psychosocial_support_23032020. pdf $>$ accessed 10 June 2020. 
These interventions are targeted to specific populations. These target groups include PUI (Persons Under Investigation) undergoing home surveillance or quarantine, healthcare workers taking care of patients in COVID-19 wards or hospitals, healthcare workers performing screening and swab collection, healthcare workers performing contact tracing at state and district levels, healthcare workers in the Crisis Preparedness and Response Centre (CPRC) at national, state and district levels who are involved in COVID-19 and responders from other agencies involved in COVID-19 such as cleaning services and waste management service workers. ${ }^{30}$

Many standardized activities are focused on the target groups, as mentioned earlier. These activities include mental health screening via online forms using the depression, anxiety and stress scale and psychological first aid to the target groups. The step after the screening is a psychological intervention, and art therapy is conducted through group or individual sessions. At the same time, outreach flyers are distributed either physically or online. The distribution of mental health alert cards is also done to raise awareness among targeted groups to seek help if symptoms of emotional disturbance are present. Consultation and treatment for persisting symptoms are referred to specialized services in hospitals. ${ }^{31}$

The delivery of MHPSS services to all victims during the COVID-19 pandemic follows the principle that basic needs shall be provided to all victims, followed by restoration of community and family support and by focused and specialized services to a smaller subgroup within those affected by the crisis. This follows the Inter-Agency Standing Committee (IASC) Guidelines for MHPSS in Emergency Settings. ${ }^{32}$ The action plan of MHPSS during the COVID-19 pandemic in Malaysia is carried out at national, state and district levels. MHPSS providers consist of public health physicians, family medicine specialists, psychiatrists,

\footnotetext{
${ }^{30}$ ibid.

${ }^{31}$ ibid.

${ }^{32}$ Inter-Agency Standing Committee, 'Interim Briefing Note Addressing Mental Health and Psychosocial Aspects COVID-19 Outbreak' (Inter-Agency Standing Committee, 2020) <https:// interagencystandingcommittee.org/iasc-reference-group-mental-health-and-psychosocial-support-emergency-settings/interim-briefing> accessed 10 June 2020.
} 
medical officers, clinical psychologists, psychology officers, paramedics (assistant medical officers and nurses), medical social workers and NGOs. The target group for MHPSS were PUI undergoing home surveillance/quarantine, health care workers (HCW) involved in COVID-19 at different levels and sectors, and responders from other agencies involved in COVID-19, for example, cleaning services and waste management service workers. ${ }^{33}$

The MHPSS activities are reported to the MHPSS coordinators at a hospital, district, and state level and finally submitted to National CPRC. There was also an outline of recommended interventions for mental health care for the general population, HCW team leaders and managers in health facilities and care providers for children. Generally, the recommendations are in accordance with the mental health and psychosocial considerations of WHO during the COVID-19 outbreak. ${ }^{34}$ The Ministry of Health also produced COVID-19 mental health kits in hospital settings and quarantine centres, which targeted patients and HCW. ${ }^{35}$

On top of these activities, collaboration and coordination of all providers of psychosocial support from various agencies are mobilized. Training of all response personnel and reports are documented. General information and tips for mental health care are distributed to the general population affected by social isolation. These tips revolve around methods to relax and reduce stress. Moreover, activities to support mental wellbeing during home surveillance are highlighted for families and children. Spotlight is given especially to basic needs such as food and care. ${ }^{36}$

Subsequently, the general population is given updated information and tips on coping with the pandemic of COVID-19. Among groups focused on are care providers for children, older adults and people with underlying health conditions. MHPSS interventions in Malaysia during the pandemic of COVID-19 are following

\footnotetext{
${ }^{33}$ Ministry of Health Malaysia (n 29).

${ }^{34}$ World Health Organization (n 23).

${ }^{35}$ Ministry of Health Malaysia, 'COVID-19 Mental Health Kit in Hospital Setting and Quarantine Centre' (Ministry of Health Malaysia, 2020) < https://www.moh.gov.my/moh/resources/ penerbitan/Garis Panduan/Umum (KKM)/Kit_Kesihatan_Mental_COVID-19.pdf.> accessed 10 June 2020.

${ }^{36}$ Inter-Agency Standing Committee (n 32).; World Health Organization (n 23).
} 
the WHO and IASC on Mental Health and Psychosocial Support in Emergency Settings. MHPSS Malaysia guidelines were written based on the WHO and IASC MHPSS guidelines; hence, all populations at risk of emotional and psychological problems during this COVID-19 pandemic were addressed. ${ }^{37}$

\section{Conclusion}

Real-time monitoring of mental health issues and the creation of treatment programmes need to be on a bigger scale than has ever been seen and must be coordinated and targeted comprehensively. It is suggested that government funding establish specialized working groups comprised of people with experience of mental health impacts to ensure research and treatment are prioritized. The scale of this problem is too serious to ignore, both in terms of the possible impact on every human life and the wider impact on society.

However, caution must be practised while evaluating and treating people who experience mental health issues as there is a legal and ethical perspective to consider. Violation of rights should be avoided in order to provide good ethical psychiatric care in the 'best interest' of the person. Ethical consideration can assist in informing and guiding those who are directly involved in moral issues in conducting mental health research. It is necessary to balance idealism with the pragmatism of how much is feasible and how much should be attempted in these studies. It is imperative to note that ethics should not become archaic impractical laws but should consist of scientifically sound, implementable guidelines that are periodically updated.

\section{Bibliography}

A. Skelton, The Stanford Encyclopedia of Philosophy (Summer 201, Metaphysics Research Lab, Stanford University 2012).

A.H. Sulaiman and others, 'Development of a Remote Psychological First Aid Protocol for Healthcare Workers Following the COVID-19 Pandemic in a University Teaching Hospital' (2020) 8 Malaysia Healthcare $<$ http://dx.doi.

${ }^{37}$ World Health Organization (n 23). 
org/10.3390/healthcare8030228>.

C. Rohde and others, Psychiatric Symptoms Related to the COVID-19 Pandemic (medRxiv 2020).

Ellen Townsend, 'Key Ethical Questions for Research during the COVID-19 Pandemic' (2020) 7 Lancet Psychiatry $<$ https://www.thelancet.com/journals/ lanpsy/article/PIIS2215-0366(20)30150-4/fulltext>.

Emily A Holmes and others, 'Multidisciplinary Research Priorities for the COVID-19 Pandemic: A Call for Action for Mental Health Science' (2020) 7 Lancet Psychiatry.

F. Hao and others, Do Psychiatric Patients Experience More Psychiatric Symptoms during COVID-19 Pandemic and Lockdown? A Case-Control Study with Service and Research Implications for Immunopsychiatry (Brain, behavior, and immunity 2020).

Felice Lasevoli and others, 'Psychological Distress in Patients with Serious Mental Illness during the COVID-19 Outbreak and One-Month Mass Quarantine in Italy' (Psychological Medicine, 2020) <https://doi.org/10.1017/ S0033291720001841>.

Florian Roth and Gabriel Brönnimann, Focal Report 8: Risk Analysis Using the Internet for Public Risk Communication (Center for Security Studies 2013).

Hemavathi Shanmugam and others, 'Impacts of COVID-19 Pandemic on Mental Health in Malaysia: A Single Thread of Hope' (2020) 29 Malaysian Journal of Psychiatry.

Inter-Agency Standing Committee, 'Interim Briefing Note Addressing Mental Health and Psychosocial Aspects COVID-19 Outbreak' (Inter-Agency Standing Committee, 2020) <https://interagencystandingcommittee.org/ iasc-reference-group-mental-health-and-psychosocial-support-emergencysettings/interim-briefing $>$ accessed 10 June 2020.

Kalina Bontcheva and others, 'Social Media and Information Overload: Survey Results' (arXiv, 2013) <https://arxiv.org/pdf/1306.0813.pdf> accessed 10 June 2020.

Lawrence O Gostin and others, 'Ethical and Legal Challenges Posed by Severe Acute Respiratory Syndrome: Implications for the Control of Severe Infectious Disease Threats' (2003) 290 JAMA < https://doi.org/10.1001/ jama.290.24.3229>. 
Malaysiakini, 'Battling the Beast within: The Psychological Trauma of Covid-19' (Malaysiakini, 2020) <https://www.malaysiakini.com/news/522732> accessed 11 September 2020.

Mark Ashworth and others, 'Physical Health in Severe Mental Illness' (2017) 67 British Journal of General Practice $<$ https://doi.org/10.3399/bjgp17X692621>.

Ministry of Health Malaysia, 'Annexe 33 Mental Health and Psychosocial Support in COVID-19' (Ministry of Health Malaysia, 2020) <https://www.moh.gov. $\mathrm{my} / \mathrm{moh} /$ resources/Penerbitan/Garis Panduan/COVID19/Annex_33_Mental_ health_and_Psychosocial_support_23032020.pdf> accessed 10 June 2020.

—-, 'COVID-19 Mental Health Kit in Hospital Setting and Quarantine Centre' (Ministry of Health Malaysia, 2020) <https://www.moh.gov.my/moh/ resources/penerbitan/Garis Panduan/Umum (KKM)/Kit_Kesihatan_Mental_ COVID-19.pdf.> accessed 10 June 2020.

News Strait Times, 'Covid-19 to Have "profound" Mental Health Fallout' (News Strait Times, 2020) <https://www.nst.com.my/world/world/2020/04/584739/ covid-19-have-profound-mental-health-fallout> accessed 10 June 2020.

S. Sundarasen and others, 'Psychological Impact of COVID-19 and Lockdown among University Students in Malaysia: Implications and Policy Recommendations' (2020) 17 International Journal of Environmental Research and Public Health $<$ http://dx.doi.org/10.3390/ijerph17176206>.

Sarah Barber and others, 'Severe Mental Illness and Risks from COVID-19' (The Centre for Evidence-Based Medicine, 2020) <https://www.cebm.net/ covid-19/severe-mental-illness-and-risks-from-covid-19/> accessed 18 September 2020 .

The Star, 'Implement Emergency Response to Domestic Violence amid Covid-19 Crisis' (The Star, 2020) <https://www.thestar.com.my/opinion/ letters/2020/04/13/implement-emergency-response-to-domestic-violenceamid-covid-19-crisis $>$ accessed 10 June 2020.

The Straits Times, 'Covid-19 Crisis Taking a Toll on Malaysians' Mental Health' (The Straits Times, 2020) < https://www.straitstimes.com/asia/se-asia/covid19-crisis-taking-a-toll-on-malaysians-mental-health $>$ accessed 11 September 2020.

Tom L. Beauchamp and James F. Childress, Principles of Biomedical Ethics (6th edn, Oxford University Press 2009).

UN General Assembly, 'Convention on the Rights of Persons with Disabilities' 
(UN General Assembly, 2006) <https://www.refworld.org/docid/4680cd212. html $>$ accessed 10 June 2020.

V. Kobbin and others, 'Fear, Anxiety and Coping Mechanism During COVID-19 Pandemic Among Undergraduate' (2020) 5 International Journal of Biomedical and Clinical Sciences.

World Health Organization, 'Mental Health and Psychosocial Considerations during the COVID-19 Outbreak' (World Health Organization, 2020) <https://www. who.int/docs/default-source/coronaviruse/mental-health-considerations.pdf> accessed 10 September 2020.

World Health Organizations, 'World Experts and Funders Set Priorities for COVID-19 Research' (World Health Organization, 2020) <https://www.who. $\mathrm{int} /$ news-room/detail/12-02-2020-world-experts-and-funders-set-prioritiesfor-covid-19-research $>$ accessed 10 June 2020.

Xuebing Liu and others, 'Clinical Characteristics of Hospitalized Patients with Schizophrenia Who Were Suspected to Have Coronavirus Disease (COVID-19) in Hubei Province, China'(2020) 33 General psychiatry $<$ https:// doi.org/10.1136/gpsych-2020-100222>.

Yaping Bao and others, '2019-NCoV Epidemic: Address Mental Health Care to Empower Society' (2019) 395 Lancet.

Zuhaira Nadia Zulkipli and others, 'Covid-19 Anxiety: Malaysian Regulatory Mechanisms On Mental Health' (2020) 29 International Journal of Advanced Science and Technology <http://sersc.org/journals/index.php/IJAST/article/ view/12723>.

HOW TO CITE: Siti Hafsyah Idris, Nor Jannah Nasution Raduan, Nurul Azreen Hashim, Nadiah Thanthawi Jauhari and Roslinda Mohd Subbian, 'The Intersection of COVID-19 and Mental Health: What's the Matter with Ethics?' (2021) 36 Yuridika. 